\title{
Mixed convection flow over a vertical plate with localized heating (cooling), magnetic field and suction (injection)
}

\author{
A. J. Chamkha, H. S. Takhar, G. Nath
}

\begin{abstract}
An analysis is carried out to study the effects of $\mathrm{Pr}$ localized heating (cooling), suction (injection), buoyancy forces and magnetic field for the mixed convection flow on a heated vertical plate. The localized heating or cooling introduces a finite discontinuity in the mathematical formulation of the problem and increases its complexity. In order to overcome this difficulty, a non-uniform distribution of wall temperature is taken at finite sections of the plate. The nonlinear coupled parabolic partial differential equations governing the flow have been solved by using an $\alpha$ implicit finite-difference scheme. The effect of the localized heating or cooling is found to be very significant on the heat transfer, but its effect on the skin friction is comparatively small. The buoyancy, magnetic and suction parameters increase the skin friction and heat transfer. The positive buoyancy force (beyond a certain value) causes an overshoot in the velocity profiles.

\section{Keywords Mixed convection, MHD}

A mass transfer constant

B magnetic field
\end{abstract}

$\mathrm{C}_{\mathrm{fx}} \quad$ skin friction coefficient in the $\mathrm{x}$-direction

$\mathrm{C}_{\mathrm{p}} \quad$ specific heat at constant pressure, $\mathrm{kJ} \cdot \mathrm{kg}^{-1} \cdot \mathrm{K}$

$\mathrm{C}_{\mathrm{v}}$ specific heat at constant volume, $\mathrm{kJ} \cdot \mathrm{kg}^{-1} \cdot \mathrm{K}^{-1}$

E electric field

g acceleration due to gravity, $9.81 \mathrm{~m} . \mathrm{s}^{-2}$

Gr Grashof number

$\mathrm{h}$ heat transfer coefficient, W. $\mathrm{m}^{2} . \mathrm{K}^{-1}$

$\mathrm{Ha}$ Hartmann number

$\mathrm{k}$ thermal conductivity, W. $\mathrm{m}^{-1} \cdot \mathrm{K}$

$\mathrm{L}$ characteristic length, $\mathrm{m}$

M magnetic parameter

$\mathrm{Nu}_{\mathrm{x}} \quad$ local Nusselt number

$\mathrm{p}$ pressure, $\mathrm{Pa}, \mathrm{N} \cdot \mathrm{m}^{-2}$

Received: 13 November 2002

Published online: 29 July 2004

(C) Springer-Verlag 2004

A. J. Chamkha

Department of Mechanical Engineering,

Kuwait University, P.O. 5969, Safat, Kuwait

H. S. Takhar ( $\square)$

Department of Engineering, Manchester Metropolitan University,

Manchester, M1 5GD, UK

E-mail: h.s.takhar@mmu.ac.uk

G. Nath

Department of Mathematics, Indian Institute of Science, Bangalore-560012, India
Prandtl number

heat flux, W.m ${ }^{-2}$

Reynolds number

magnetic Reynolds number

temperature, $\mathrm{K}$

constant plate temperature, $\mathrm{K}$ velocity components, $\mathrm{m} \cdot \mathrm{s}^{-1}$

characteristic velocity, $\mathrm{m} . \mathrm{s}^{-1}$

Cartesian coordinates

thermal diffusivity, $\mathrm{m}^{2} . \mathrm{s}^{-1}$

coefficient of thermal expansion, $\mathrm{K}^{-1}$

transformed similarity variables

dynamic viscosity, $\mathrm{kg} \cdot \mathrm{m}^{-1} \cdot \mathrm{s}^{-1}$

magnetic permeability

kinematic viscosity, $\mathrm{m}^{2} . \mathrm{s}^{-1}$

density, kg. $\mathrm{m}^{-3}$

buoyancy parameter

electrical conductivity

stream function, $\mathrm{m}^{2} \cdot \mathrm{s}^{-1}$

dimensionless constant

dimensionless temperature, $\mathrm{K}$

conditions at the wall and at infinity
1

\section{Introduction}

The process of heat transfer by mixed convection flow over vertical surfaces occurs in many industrial and technical applications which include nuclear reactors cooled during emergency shut down, electronic devices cooled by fans, solar central receivers exposed to wind currents, and heat exchangers placed in a low velocity environment. In the study of fluid flow over heated surfaces, the buoyancy forces are, generally, neglected when the flow is horizontal. However, for vertical or inclined surfaces, the buoyancy forces exert strong influence on the flow field. Hence, it is not possible to neglect the effect of buoyancy forces for vertical or inclined surfaces. Merkin [1] investigated the mixed convection boundary layer flow on a semi-infinite vertical flat plate when the buoyancy forces aid and oppose the development of the boundary layer. In this study two series solutions were obtained,one of which is valid near the leading edge and the other is valid asymptotically. In the regions where the series solutions are not valid, numerical solutions were obtained. Lloyd and Sparrow [2], Oosthuizen and Hart [3] and Wilks [4] have carried out a numerical study of the combined forced and free 
convection flow over a vertical plate. Mucoglu and Chen [5] have studied the mixed convection flow over an inclined surface for both the assisting and the opposing buoyancy forces. The partial differential equations governing the flow have been solved by using the Keller box finite-difference method [6, 7]. Also, these equations were solved by employing the local similarity and local nonsimilarity methods. Ramachandran et.al. [8,9] have studied the mixed convection flow over vertical and inclined surfaces, theoretically as well as experimentally. Merkin and Mahmood [10] have obtained the similarity solution of the mixed convection flow over a vertical plate for the constant heat flux case. Wickern $[11,12]$ has examined the influence of the inclination angle of the plate and the Prandtl number on the mixed convection flow over an inclined plate. Tsuruno and Iguchi [13] and Watanabe [14] have investigated the effects of the surface mass transfer on the mixed convection flow on a permeable vertical surface. Hossain and Ahmed [15] have examined the effect of the magnetic field on the mixed convection flow over a semi-infinite vertical plate. In recent years, several investigators [16-22] have considered various aspects of the mixed convection problem such as the variable wall heat flux, viscous dissipation effects, magnetic field, moving surface, porous medium, wall transpiration, etc.

The aim of this investigation is to consider the effects of heating or cooling of certain portions of the surface on the steady laminar mixed convection flow over a permeable vertical plate. The magnetic field is applied normal to the surface. It may be remarked that the increase or reduction of wall temperature or mass transfer (sujection/injection) in a certain section of the surface introduces a discontinuity at the leading and trailing edge of the slot which causes difficulty in the numerical solution of the governing equations. Hence we have chosen a function representing the distribution of the wall temperatures or mass transfer in the slot which varies slowly with the stream wise distance and is continuous in the slot. The coupled nonlinear parabolic partial differential equations governing the nonsimilar flow have been solved numerically using an implicit finite-difference method similar to that of Blottner [23]. The results have been compared with those of Mucoglu and Chen [5] and Watanabe [14]. The present study may be useful in the cooling of nuclear reactors during emergency shutdown, where a part of the surface can be cooled by injecting a coolant. The reactors can also be cooled by removing the heat source through a certain section of the surface

\section{2}

\section{Problem formulation}

The physical system investigated here is shown in Fig. 1. We have chosen the Cartesian $\mathrm{x}-\mathrm{y}$ coordinate system where $\mathrm{x}$ is measured along the plate and $\mathrm{y}$ is normal to the plate. We consider the steady laminar mixed convection flow of a viscous incompressible electrically conducting fluid over a permeable heated vertical plate. The plate is assumed to be electrically non-conducting. The gravity vector $\mathbf{g}$ acts in the negative $\mathrm{x}$ direction. The density variation is neglected except where it is necessary

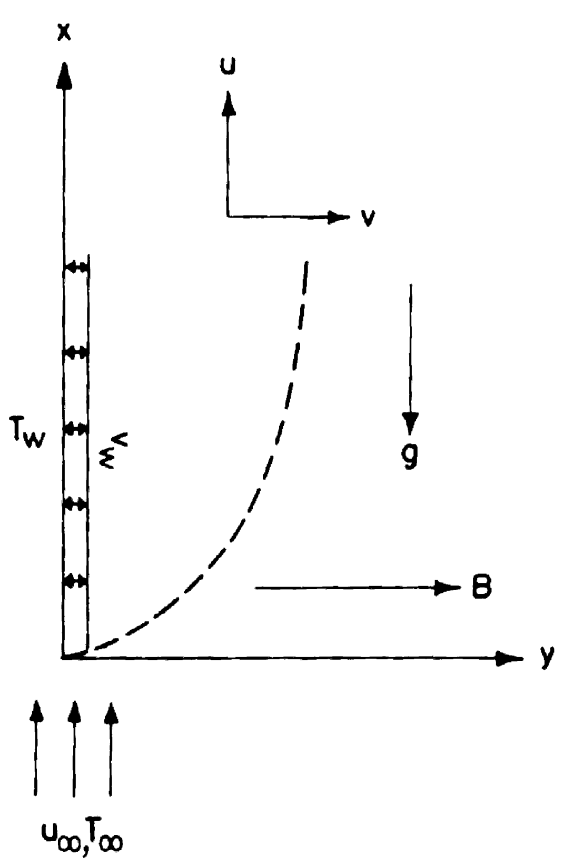

Fig. 1. Physical model and coordinate system

to drive the buoyancy forces. The free stream velocity $\mathrm{u}_{\infty}$ and the free stream temperature $\mathrm{T}_{\infty}$ are taken as constants. The surface of the heated plate is maintained at a constant temperature $\mathrm{T}_{0}\left(\mathrm{~T}_{0}>\mathrm{T}_{\infty}\right)$ except at a certain portion of the plate $\left[\mathrm{x}_{\mathrm{i}}, \mathrm{x}_{\mathrm{j}}\right]$ where it varies with the streamwise distance $x$. A magnetic field of strength $B$ is applied normal to the plate in the y-direction. It is assumed that the magnetic Reynolds number is small i.e. $\mathrm{Re}_{\mathrm{m}}=\mu_{0} \sigma \mathrm{VL} \ll 0$ and $\sigma$ are, respectively, the magnetic permeability and electrical conductivity, and $\mathrm{V}$ and $\mathrm{L}$ are the characteristic velocity and length, respectively. Under these conditions, it is possible to neglect the induced magnetic field in comparison to the applied magnetic field. Since there is no applied or polarized voltage imposed on the flow field, the electric field $\mathbf{E}=0$. Hence, the applied magnetic field contributes only to the Lorentz force which acts in the $\mathrm{x}$-direction. The viscous dissipation, Ohmic heating and the Hall effects are neglected. Under the above assumptions, the boundary layer equations for the transport of mass, momentum and energy governing the mixed convection flow over a vertical plate can be expressed as $[1,5,14,24]$;

$\mathrm{u}_{\mathrm{x}}+\mathrm{v}_{\mathrm{y}}=0$,

$\mathrm{uu}_{\mathrm{x}}+\mathrm{vu}_{\mathrm{y}}=-\rho^{-1} \mathrm{px}+v \mathrm{u}_{\mathrm{yy}}+\mathrm{g} \beta\left(\mathrm{T}-\mathrm{T}_{\infty}\right)-\sigma \rho^{-1} \mathrm{~B}^{2} \mathrm{u}$

$\mathrm{uT}_{\mathrm{x}}+\mathrm{vT}_{\mathrm{y}}=\alpha \mathrm{T}_{\mathrm{yy}}$

where $-\rho^{-1} \mathrm{px}=\mathrm{u}_{\infty}\left(\mathrm{du}_{\infty} / \mathrm{dx}\right)+\sigma \rho^{-1} \mathrm{~B}^{2} \mathrm{u}=\sigma \rho^{-1} \mathrm{~B}^{2} \mathrm{u}$, since the free stream velocity $\mathrm{u}_{\infty}$ is a constant.

The boundary conditions are the no-slip conditions on the surface and the free stream conditions at the edge of the boundary layer. These conditions are given by; 
$\mathrm{u}(\mathrm{x}, 0)=0, \mathrm{v}(\mathrm{x}, 0)=\mathrm{v}_{\mathrm{W}}, \mathrm{T}(\mathrm{x}, 0)=\mathrm{T}_{\mathrm{w}}(\mathrm{x})$ for $\mathrm{x}_{\mathrm{i}} \leq \mathrm{x} \leq \mathrm{x}_{\mathrm{j}}$

$\mathrm{T}(\mathrm{x}, 0)=\mathrm{T}_{0}$ for $0 \leq \mathrm{x}<\mathrm{x}_{\mathrm{i}}, \mathrm{x}>\mathrm{x}_{\mathrm{j}}$,

$\mathrm{u}(\mathrm{x}, \infty)=\mathrm{u}_{\infty}, \mathrm{T}(\mathrm{x}, \infty)=\mathrm{T}_{\infty}$

$\mathrm{u}(0, \mathrm{y})=\mathrm{u}_{\infty}, \mathrm{T}(0, \mathrm{y})=\mathrm{T}_{\infty}, \mathrm{y}>0$,

where

$\mathrm{T}_{\mathrm{w}}(\mathrm{x})=\mathrm{T}_{\infty}+\left(\mathrm{T}_{0}-\mathrm{T}_{\infty}\right)\left[1+\varepsilon\left(\mathrm{x}-\mathrm{x}_{\mathrm{i}}\right)\left(\mathrm{x}_{\mathrm{j}}-\mathrm{x}\right) /\left(\mathrm{x}_{\mathrm{j}}-\mathrm{x}_{\mathrm{i}}\right)^{2}\right]$.

Here $\mathrm{x}$ and $\mathrm{y}$ are distances along and perpendicular to the surface, respectively; $\mathrm{u}$ and $\mathrm{v}$ are the velocity components along the $\mathrm{x}$ and $\mathrm{y}$ directions, respectively; $v$ is the kinematic viscosity; $\mathbf{g}$ is the gravitational acceleration; $\beta$ is the coefficient of thermal expansion; $\rho$ is the density; T is the temperature; $\sigma$ is the electrical conductivity; $\mathbf{B}$ is the magnetic field; $\alpha$ is the thermal diffusivity; $\mathrm{v}_{\mathrm{w}}$ is the velocity normal to the plate which is assumed to be constant, $\epsilon$ is a dimensionless constant; the subscripts $\mathrm{x}$ and $\mathrm{y}$ denote partial derivatives with respect to $\mathrm{x}$ and $\mathrm{y}$, respectively; and the subscripts $\mathrm{w}$ and $\infty$ denote conditions at the wall and in the freestream, respectively.

It is convenient to reduce Eqs. (1)-(3) to a dimensionless form by applying the following transformations;:

$\eta=\left(\mathrm{u}_{\infty} / v \mathrm{x}\right)^{1 / 2} \mathrm{y}, \xi=\mathrm{x} / \mathrm{L}, \psi(\mathrm{x}, \mathrm{y})=\left(v \mathrm{u}_{\infty} \xi\right)^{1 / 2} \mathrm{f}(\xi, \eta)$,

$\mathrm{u}=\partial \psi / \partial y, \mathrm{v}=-\partial \psi / \partial \mathrm{x}, \mathrm{T}(\mathrm{x}, \mathrm{y})-\mathrm{T}_{\infty}=\left(\mathrm{T}_{0}-\mathrm{T}_{\infty}\right) \theta(\xi, \eta)$,

$\mathrm{Gr}_{\mathrm{L}}=\mathrm{g} \beta\left(\mathrm{T}_{0}-\mathrm{T}_{\infty}\right) \mathrm{L}^{3} / v^{2}, \mathrm{Re}_{\mathrm{L}}=\mathrm{u}_{\infty} \mathrm{L} / \mathrm{v}$,

$\lambda=\mathrm{Gr}_{\mathrm{L}} / \operatorname{Re}_{\mathrm{L}}^{2}, \operatorname{Pr}=v / \alpha$,

$\mathrm{M}=\mathrm{Ha} / \mathrm{Re}_{\mathrm{L}}, \mathrm{Ha}=\sigma \mathrm{B}^{2} \mathrm{~L}^{2} / \mu, \mathrm{A}=-\left(\mathrm{v}_{w} / \mathrm{u}_{\infty}\right) \mathrm{Re}_{\mathrm{L}}^{1 / 2}$.

Equation (1) is identically satisfied and Eqs. (2) and (3) reduce to;

$$
\begin{aligned}
& \mathrm{f}^{\prime \prime \prime}+2^{-1} \mathrm{ff}^{\prime \prime}+\lambda \xi \theta+\mathrm{M} \xi\left(1-\mathrm{f}^{\prime}\right) \\
& \quad=\xi\left(\mathrm{f}^{\prime} \partial \mathrm{f}^{\prime} / \partial \xi-\mathrm{f}^{\prime \prime} \partial \mathrm{f} / \partial \xi\right) \\
& \theta^{\prime \prime \prime}+2^{-1} \operatorname{Pr} \mathrm{f}^{\prime}=\operatorname{Pr} \xi\left(\mathrm{f}^{\prime} \partial \theta / \partial \xi=\theta^{\prime} \partial \mathrm{f} / \partial \xi\right) .
\end{aligned}
$$

The boundary conditions (4) can be expressed as

$$
\begin{aligned}
& \mathrm{f}(\xi, 0)=\mathrm{A} \xi^{1 / 2}, \mathrm{f}^{\prime}(\xi, 0)=0, \\
& \theta(\xi, 0)=1+\varepsilon\left[\left(\xi-\xi_{\mathrm{i}}\right)\left(\xi_{\mathrm{j}}-\xi\right) /\left(\xi_{\mathrm{j}}-\xi_{\mathrm{i}}\right)^{2}\right] \text { for } \xi_{\mathrm{i}} \leqslant \xi \leqslant \xi_{j}, \\
& \theta(\xi, 0)=1 \text { for } \xi<\xi_{\mathrm{i}}, \xi>\xi_{\mathrm{j}}, \\
& \mathrm{f}^{\prime}(\xi, \infty)=1, \theta(\xi, \infty)=0 .
\end{aligned}
$$

Here $\xi$ and $\eta$ are the transformed coordinates; $\Psi$ and $\mathrm{f}$ are the dimensional and dimensionless stream functions, respectively; $\mathrm{f}^{\prime}$ and $\theta$ are the dimensionless velocity and temperature, respectively; $\mathrm{Gr}_{\mathrm{L}}$ and $\mathrm{Re}_{\mathrm{L}}$ are the Grashof number and Reynolds number, respectively; $\lambda$ is the buoyancy parameter which is the ratio of the Grashof number to the Reynolds number squared; $M$ is the magnetic parameter which is the ratio of the Hartmann number to the Reynolds number; $\mathrm{Ha}$ is the Hartmann number; $\mu$ is the coefficient of viscosity; $A$ is the mass transfer parameter and $\mathrm{A}>$ or $<0$ according to whether there is suction and injection; prime denotes derivative with respect to $\eta$; and $\epsilon$ is a constant and $\epsilon>$ or $<0$ according to whether the wall is being heated or cooled. For $\epsilon=0$, the entire wall is maintained at a constant temperature $\mathrm{T}_{0}\left(>\mathrm{T}_{\infty}\right)$.

It may be remarked that Eqs. (6) and (7) under the boundary conditions (8) for $\epsilon=0$ (uniform wall temperature), $\mathrm{A}=0$ (no mass transfer) and $\mathrm{M}=0$ (without the magnetic field) reduce to those of Mucoglu and Chen [5] and for $\epsilon=\mathrm{M}=0$ to those of Watanabe [14] if we replace $\lambda \xi$ by $\xi$ in equation (6). In references [5] and [14], $\xi=\mathrm{Gr}_{\mathrm{x}} / \mathrm{Re}^{2}{ }_{\mathrm{x}}=\left(\mathrm{Gr}_{\mathrm{L}} / \mathrm{Re}^{2}{ }_{\mathrm{L}}\right)(\mathrm{x} / \mathrm{L})$, which becomes $\lambda \xi$ in our notation.

It is noted that the dimensionless wall temperature $\theta(\xi$, 0 ) given by Eq. (8) is a continuous function of the dimensionless streamwise distance $\xi$, with a small change in the interval $\left[\xi_{\mathrm{i}}, \xi_{\mathrm{j}}\right]$ over the constant value of 1 . The increase or reduction in the wall temperature in the interval by a constant value introduces a finite discontinuity at the leading and trailing edges of the slot and this causes numerical difficulties in the solution of the equations. In order to avoid these difficulties, we have taken a non-uniform distribution of wall temperature in the interval $\left[\xi_{\mathrm{i}}, \xi_{\mathrm{j}}\right]$ which varies slowly with $\xi$.

The quantities of physical interest are the local skin friction coefficient and the local heat transfer coefficient, and these are given by;

$$
\begin{aligned}
& \mathrm{C}_{\mathrm{fx}}=\mu(\partial u / \partial \mathrm{y})_{\mathrm{y}=0} / \rho \mathrm{u}_{\infty}^{2}=\mathrm{Re}_{\mathrm{x}}^{-1 / 2} \mathrm{f}^{\prime \prime}(\xi, 0), \\
& \mathrm{Nu}_{\mathrm{x}}=-\mathrm{k}(\partial \mathrm{T} / \partial \mathrm{y})_{\mathrm{y}=0} /\left(\mathrm{T}_{0}-\mathrm{T}_{\infty}\right)=-\operatorname{Re}_{x}^{1 / 2} \theta^{\prime}(\xi, 0),
\end{aligned}
$$

where $\mathrm{C}_{\mathrm{fx}}$ and $\mathrm{Nu}_{\mathrm{x}}$ are the local skin friction coefficient and the local Nusselt number, respectively, and $\operatorname{Re}_{\mathrm{x}}\left(\mathrm{u}_{\infty} \mathrm{x} /\right.$ $v$ ) is the local Reynolds number.

\section{3}

\section{Method of solution}

The coupled nonlinear parabolic partial differential Eqs. (6) and (7) under the boundary conditions (8) have been solved numerically using an implicit iterative tridiagonal finite-difference method which is similar to that discussed by Blottner [23]. All the first-order derivatives with respect to $\xi$ are replaced by the two-point backward difference formulae of the form;

$\partial \mathrm{R} / \partial \xi=\left(\mathrm{R}_{\mathrm{m}, \mathrm{n}}-\mathrm{R}_{\mathrm{m}-1, \mathrm{n}}\right) / \Delta \xi$,

where $\mathrm{R}$ represents dependent variable f or $\theta$, and $\mathrm{m}$ and $\mathrm{n}$ are the node locations along the $\xi$ and $\eta$ directions,

respectively. First, the third-order partial differential Eq. (6) is converted into a second-order by substituting $f^{\prime}=F$. Then the second-order partial differential equations for $\mathrm{F}$ and $\theta$ are discretized by using three-point central difference formulae, while the first-order differential equations are discretized by employing the trapezoidal rule. At each line of constant $\xi$, we get a system of algebraic equations. The nonlinear terms are evaluated at the previous iteration and the system of algebraic equations are solved iteratively by using the Thomas algorithm (see Blottner [23]). The same procedure is repeated for the next $\xi$ value and the problem is 
solved line by line until the desired $\xi$ value is reached. A convergence criterion based on the relative difference between the current and previous iterations is used. When this difference becomes $10^{-5}$, the solution is assumed to have converged and the iterative process is terminated.

The effects of the grid sizes $\Delta \eta$ and $\Delta \xi$, and the edge of the boundary layer $\eta_{\infty}$ on the solution have been examined. The results presented here are nearly independent of $\Delta \eta, \Delta \xi$ and $\eta$, at least up to the fourth decimal place.

\section{4}

\section{Results and discussion}

Equations (6) and (7) under the boundary boundary conditions (8) have been solved numerically using the finite-difference scheme described earlier. The results have been presented for various values of the parameters $M$ $(0 \leq \mathrm{M} \leq 4), \lambda(-0.5 \leq \lambda \leq 5), \mathrm{A}(-1 \leq \mathrm{A} \leq 1),-0.25$ $\leq \varepsilon \leq 0.25$, and $\operatorname{Pr}=0.7$.

In order to assess the accuracy of our method, we have compared the local skin friction coefficient $\left(\operatorname{Re}_{\mathrm{x}}{ }^{1 / 2} \mathrm{C}_{\mathrm{fx}}\right)$ and local Nusselt number $\left(\mathrm{Re}_{\mathrm{x}}{ }^{-1 / 2} \mathrm{Nu}_{\mathrm{x}}\right)$ for $\mathrm{M}=0$ (without the magnetic field), $\mathrm{A}=0$ (without the mass transfer) and $\epsilon$ $=0$ (without the wall heating or cooling) with those of Mucoglu and Chen [5] and for $\mathrm{M}=\epsilon=0$ with those of Watanabe [14]. The results are found to be in very good agreement. The maximum difference is about 1 percent. Hence for the sake of brevity the comparison is not shown here.

It may be noted that for computation purposes, we have taken two slots located in the intervals $[0.1,0.3]$ and $[0.6$, $0.8]$. The wall is heated or cooled in these intervals only. In the remaining portion, the wall is at a constant temperature $\mathrm{T}_{0}\left(>\mathrm{T}_{\infty}\right)$.

Figures 2 and 3 show the effects of the wall heating or cooling in the two slots $(-0.25 \varepsilon \leq \varepsilon \leq 0.5)$ as well the magnetic parameter $M$ on the local skin friction coefficient $\left(\operatorname{Re}_{\mathrm{x}}{ }^{1 / 2} \mathrm{C}_{\mathrm{fx}}\right)$ and the local Nusselt number $\left(\mathrm{Re}_{\mathrm{x}}{ }^{-112} \mathrm{Nu}_{\mathrm{x}}\right)$. The effects of wall heating $(\epsilon>0)$ and wall cooling $(\epsilon<0)$ in two slots are found to be more pronounced on the

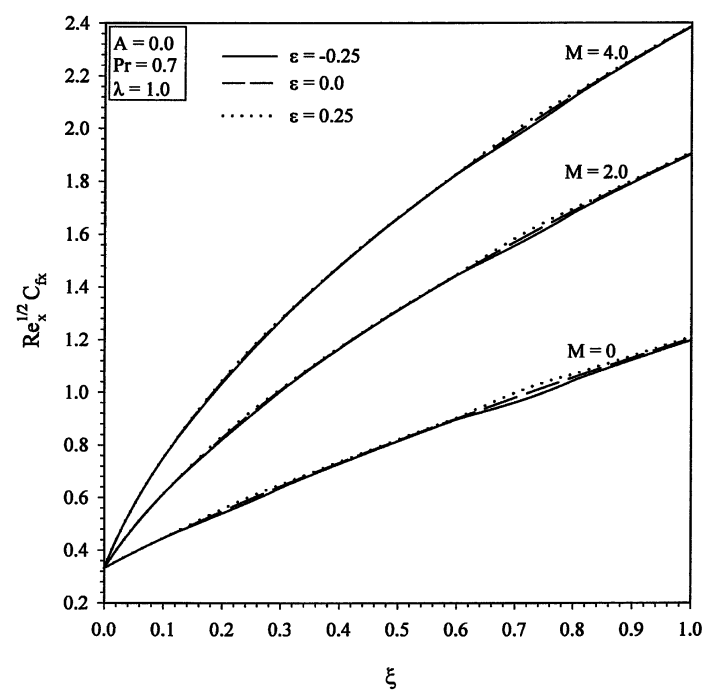

Fig. 2. Effects of wall heating and cooling $(\epsilon=-0.25,0,0.25)$ and the magnetic parameter $(\mathrm{M})$ on the local skin friction coefficient $\left(\operatorname{Re}_{\mathrm{x}}{ }^{1 / 2} \mathrm{C}_{\mathrm{fx}}\right)$

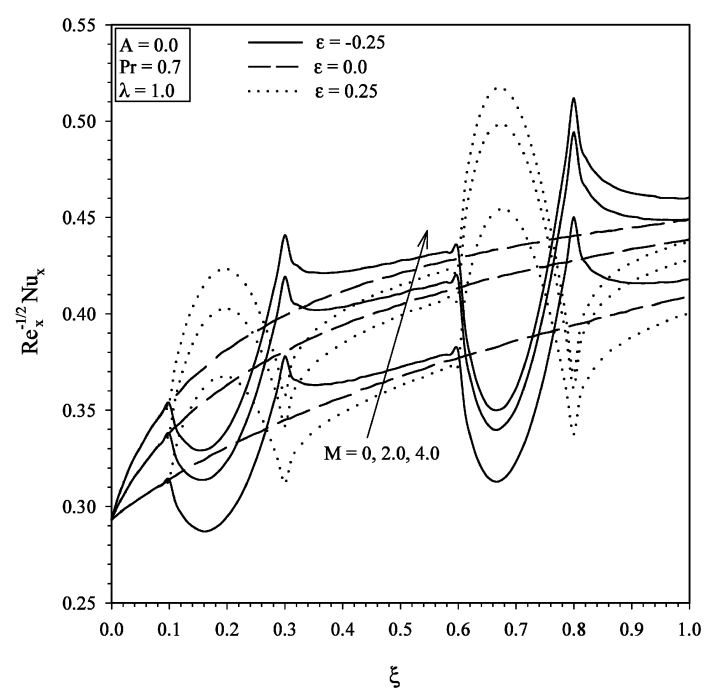

Fig. 3. Effects of wall heating and cooling $(\epsilon=-0.25,0,0.25)$ and the magnetic parameter $(\mathrm{M})$ on the local Nusselt number $\left(\operatorname{Re}_{\mathrm{x}}{ }^{-1 / 2} \mathrm{Nu}_{\mathrm{x}}\right)$

Nusselt number $\left(\operatorname{Re}_{\mathrm{x}}{ }^{-1 / 2} \mathrm{Nu}_{\mathrm{x}}\right)$ than on the skin friction coefficient $\left(\operatorname{Re}_{\mathrm{x}}{ }^{1 / 2} \mathrm{C}_{\mathrm{fx}}\right)$, because the wall heating/cooling directly affects the thermal field, whereas its effect on the velocity field is only indirect. In the region beyond the slots, the Nusselt number for the wall cooling is higher than that of the wall heating. The reason for this trend is that for the wall cooling the temperature difference between the wall and fluid near the wall increases. Consequently, the temperature gradient and hence the heat transfer (Nusselt number) increase. The effect of the wall heating is opposite to that of the wall cooling, but it is not a mirror reflection of the wall cooling. Since the temperature of the wall in the slots are changed, significant changes take place in the vicinity of the trailing edge of these slots. Generally, the changes are more near to the trailing edge of the second slot, because it also carries the perturbation caused by the first slot. Further, both the skin friction and the Nusselt number increase with the magnetic parameter $\mathrm{M}$, due to the enhanced Lorentz force which accelerates the motion. Consequently, both the momentum and the thermal boundary layers are reduced. Hence the skin friction and the Nusselt number are increased due to the presence of the magnetic field. Since the magnetic parameter $M$ is multiplied by $\xi$ (see Eq. (6)), the effect of $M$ increases with the streamwise distance $\xi$.

Figures 4 and 5 present the effect of the buoyancy parameter $\lambda$ on the velocity and the temperature profiles $\left(\mathrm{f}^{\prime}(\xi, \eta), \theta(\xi, \eta)\right)$. It is evident from these figures that for an assisting flow $(\lambda>0)$, the velocity and temperature gradients increase with $\lambda$ and the momentum and thermal boundary layers decrease. Since the positive buoyancy force acts like a favourable pressure gradient, it accelerates the fluid in the boundary layer. Consequently both the momentum and the thermal boundary layers are reduced and the velocity and the temperature gradients are increased. For $\lambda>1.6$ and $\operatorname{Pr}=0.7$, the velocity $\left(\mathrm{f}^{\prime}(\xi, \eta)\right)$ near the wall exceeds the velocity beyond its free stream value. Similar trend has been observed by Mucoglu and Chen [5] and Watanabe [14]. 


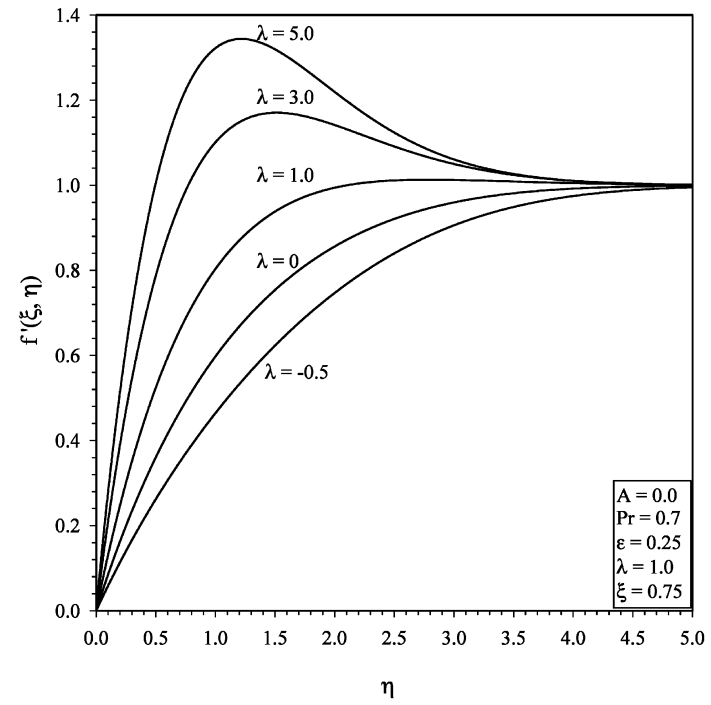

Fig. 4. Effect of the buoyancy parameter $(\lambda)$ on the velocity profiles $\left(\mathrm{f}^{\prime}(\xi, \eta)\right)$

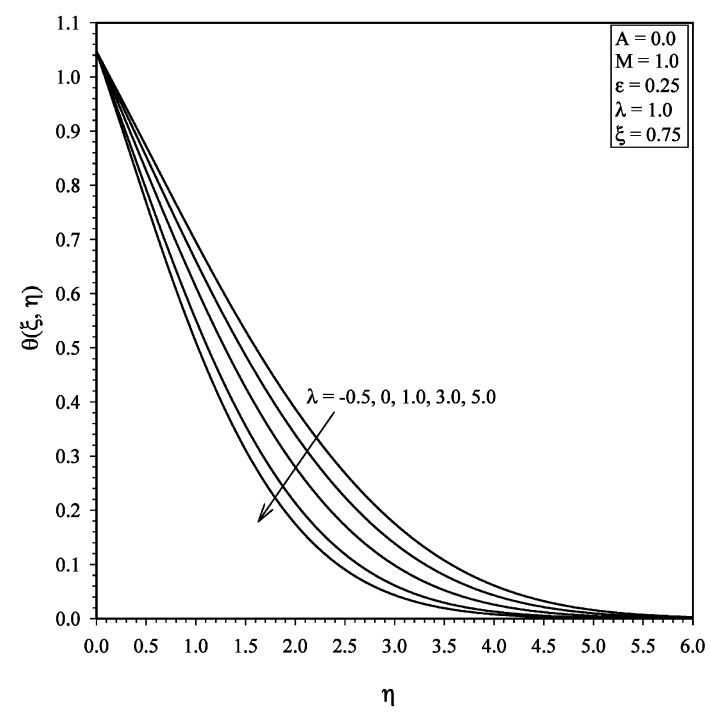

Fig. 5. Effect of the buoyancy parameter $(\lambda)$ on the temperature profiles $(\theta(\xi, \eta))$

In Figs. 6 and 7 the effects of the buoyancy parameter $\lambda$ on the local skin friction coefficient $\left(\operatorname{Re}_{\mathrm{x}}{ }^{1 / 2}, \mathrm{C}_{\mathrm{fx}}\right)$ and the local Nusselt number $\left(\operatorname{Re}_{\mathrm{x}}{ }^{1 / 2} \mathrm{Nu}_{\mathrm{x}}\right)$ are displayed. As mentioned earlier for assisting flow $(\lambda>0)$, the buoyancy parameter $\lambda$ acts like a favourable pressure gradient and increases the fluid motion. Hence both the skin friction and the heat transfer are increased due to the increasing buoyancy force. The effect of $\lambda$ on the skin friction and Nusselt number increases with the streamwise distance $\xi$, because Eq. (6) contains the terms $\lambda \xi$. Since the effects of heating and cooling of the wall $(\epsilon \neq 0)$ on $\mathrm{Re}_{\mathrm{x}}{ }^{1 / 2} \mathrm{C}_{\mathrm{fx}}$ and $\mathrm{Re}_{\mathrm{x}}{ }^{-1 / 2} \mathrm{Nu}_{\mathrm{x}}$ have already been discussed, it is not discussed here.

Figures 8 and 9 show the effect of the mass transfer parameter $A$ on the velocity and temperature profiles $\left(\mathrm{f}^{\prime}(\xi\right.$, $\eta), \theta(\xi, \eta))$. Since the effect of suction is to suck away the

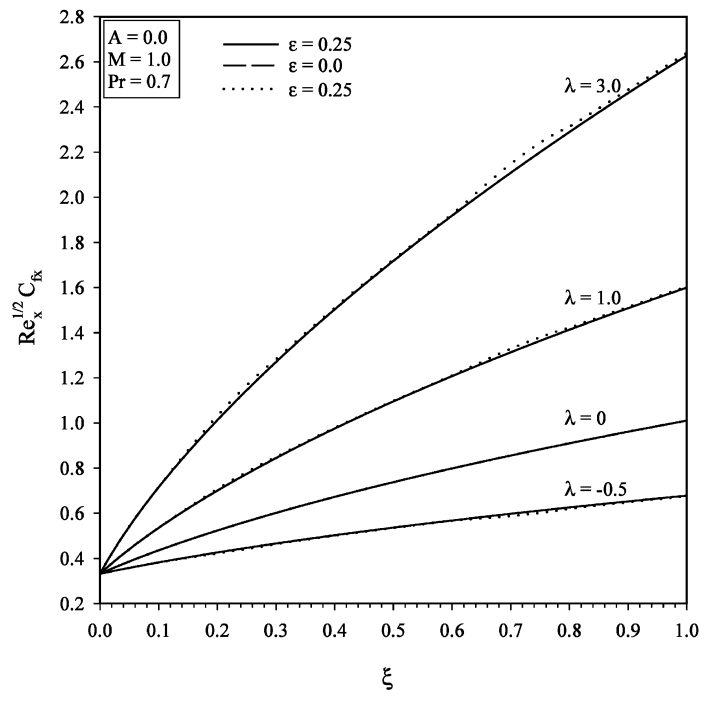

Fig. 6. Effects of wall heating and cooling $(\epsilon=-0.25,0,0.25)$ and the buoyancy parameter $(\lambda)$ on the skin friction coefficient $\left(\mathrm{Re}_{\mathrm{x}}{ }^{1 / 2} \mathrm{C}_{\mathrm{fx}}\right)$

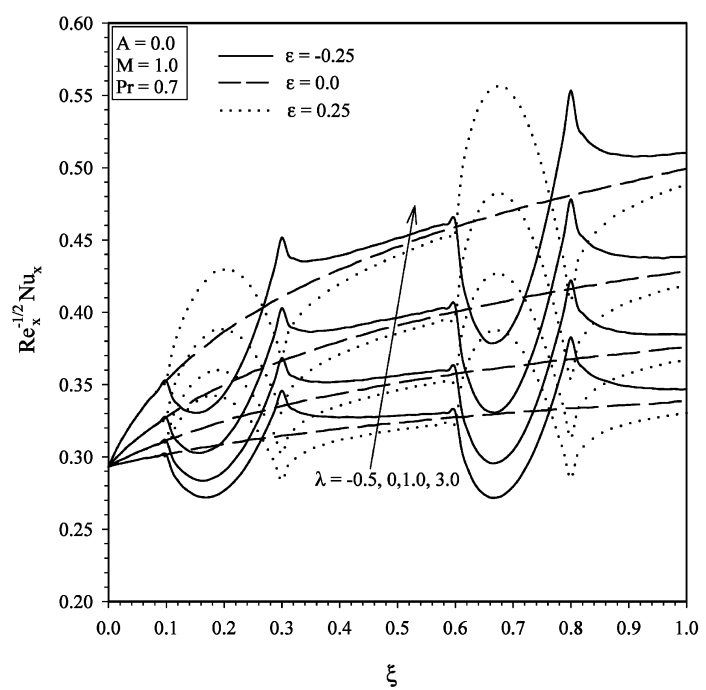

Fig. 7. Effects of wall heating and cooling $(\epsilon=-0.25,0,0.25)$ and the buoyancy parameter $(\lambda)$ on the local Nusselt number $\left(\mathrm{Re}_{\mathrm{x}}{ }^{-1 / 2} \mathrm{Nu}_{\mathrm{x}}\right)$

fluid near the wall, both the momentum and thermal boundary layers are reduced due to suction $(A>0)$. Consequently the velocity increases with $\mathrm{A}$, but the temperature decreases. Further both the momentum and the thermal boundary layers decrease with increasing A (A > $0)$, but the velocity and temperature gradients increase.

The effects of suction $(A>0)$ and injection $(A<0)$ on the skin friction coefficient $\left(\operatorname{Re}_{\mathrm{x}}{ }^{1 / 2} \mathrm{C}_{\mathrm{fx}}\right)$ and the Nusselt number $\left(\operatorname{Re}_{\mathrm{x}}{ }^{-1 / 2} \mathrm{Nu}_{\mathrm{x}}\right)$ are shown in Figs. 10 and 11. As mentioned earlier, suction $(\mathrm{A}>0)$ reduces both the thermal and momentum boundary layer thicknesses. Consequently, the velocity and temperature gradients and hence the skin friction and heat transfer increase with $\mathrm{A}(\mathrm{A}>0)$. The effect of injection $A(A<0)$ is opposite to that of 


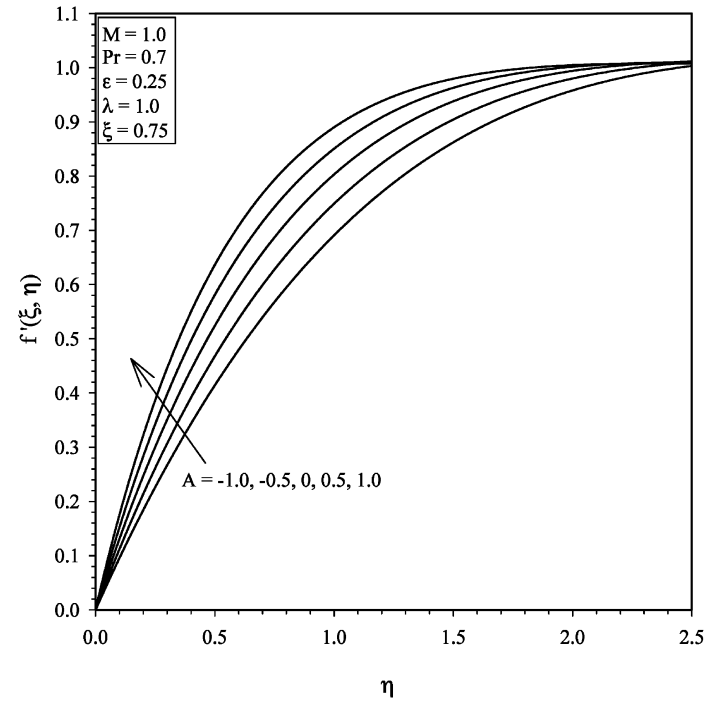

Fig. 8. Effect of the mass transfer (A) on the velocity profiles $\left(\mathrm{f}^{\prime}(\xi, \eta)\right)$

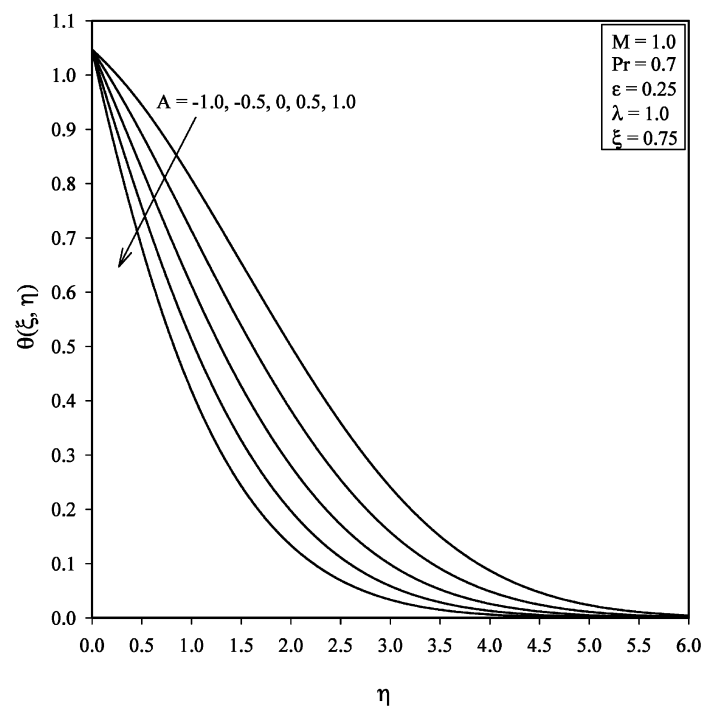

Fig. 9. Effect of the mass transfer (A) on the temperature profiles $(\theta(\xi, \eta))$

suction, but it is not a mirror reflection of suction. The effect of the mass transfer parameter $A$ increases with the streamwise distance $\xi$. This is due to the fact that A is multiplied by $\xi^{1 / 2}$ (see Eq. (8)).

\section{5}

\section{Conclusions}

The localized cooling and heating of the wall exerts a strong influence on the heat transfer and large change takes place in the slot as well as in the vicinity of the trailing edge of the slot. The skin friction and the heat transfer increase with increasing buoyancy force, magnetic field, suction parameter and the streamwise distance. The buoyancy force (which assists the flow) beyond a certain value induces an overshoot in the velocity profiles. The effects of the partial cooling of the wall and injection are

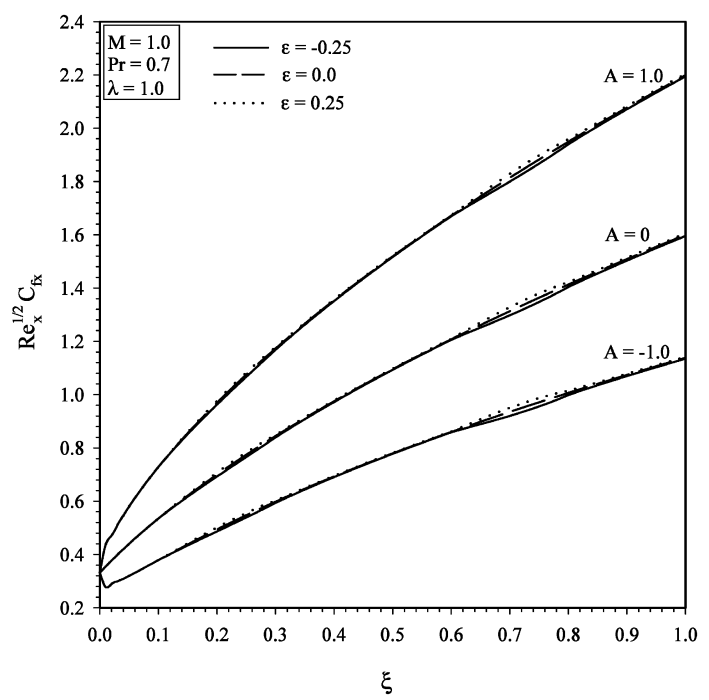

Fig. 10. Effects of wall heating and cooling $(\epsilon=-0.25,0,0.25)$ and mass transfer parameter (A) on the local skin friction coefficient $\left(\operatorname{Re}_{\mathrm{x}}{ }^{1 / 2} \mathrm{C}_{\mathrm{fx}}\right)$.

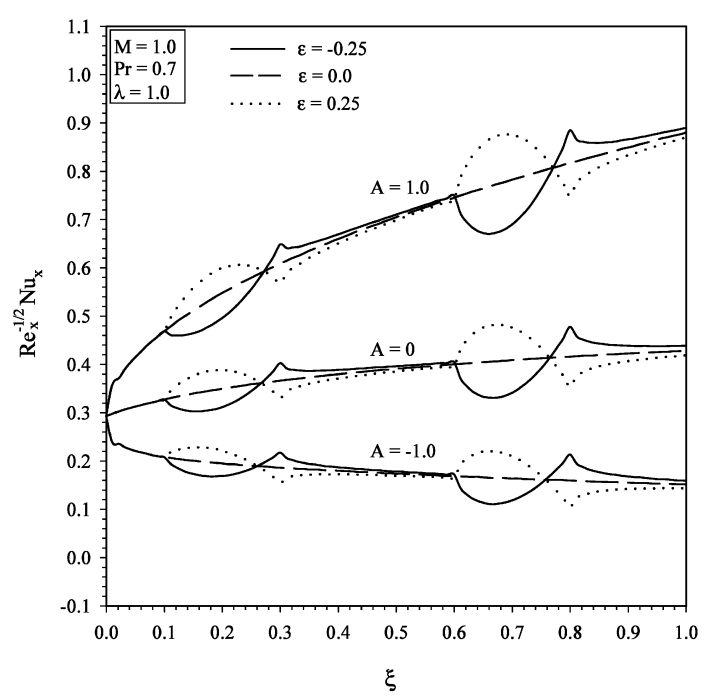

Fig. 11. Effects of wall heating and cooling $(\epsilon=-0.25,0,0.25)$ and mass transfer parameter $(\mathrm{A})$ on the local Nusselt number $\left(\mathrm{Re}_{\mathrm{x}}{ }^{-1 / 2}\right.$ $\mathrm{Nu}_{\mathrm{x}}$ )

not a mirror reflection of the partial heating and suction, respectively.

\section{References}

1. Merkin JH (1969) The effects of buoyancy forces on the boundary layer flow over a semi-infinite vertical flat plate in a uniform stream, J Fluid Mech 35: 439-450

2. Lyod JR; Sparrow EM (1970) Combined forced and free convection flow on vertical surfaces. Int J Heat Mass Transfer 13: 434-438

3. Oosthuizen PH; Hart H (1973) A numerical study of laminar combined convection flow over a flat plate. J Heat Transfer 95 60-63

4. Wilks G (1973) Combined forced and free convection flow on vertical surfaces. Int J Heat Mass Transfer 16: 1958-1966

5. Mucoglu A; Chen TS (1979) Mixed convection on inclined surfaces. J Heat Transfer 10: 422-426

6. Cebeci T; Bradshaw P (1977) Momentum transfer in boundary layers. Hemisphere Publishing Corporation, Washington D.C. USA 
7. Cebeci T; Bradshaw P (1984) Physical and computational aspects of convective heat transfer. Springer Verlag, New York, USA

8. Ramachandran N; Armaly BF; Chen TS (1985) Measurements and predictions of laminar mixed convection flow adjacent to a vertical surface. J Heat Transfer 107: 636-641

9. Ramachandran N; Armaly BF; Chen TS (1987) Measurements of laminar mixed convection flow adjacent to an inclined surface. J Heat Transfer 109: 146-151

10. Merkin JH; Mahmood T (1989) Mixed convection boundary layer similarity solution : prescribed wall heat flux. ZAMP 40: 61-68

11. Wickern G (1991) Mixed convection from an arbitrarily inclined semi-infinite flat plate-I The influence of the inclination angle. Int J Heat Mass Transfer 34: 1935-1945

12. Wickern G (1991), Mixed convection from an arbitrarily inclined semi-infinite flat plate-II. The influence of the Prandtl number. Int J Heat Mass Transfer 34: 1947-1957

13. Tsuruno S; Iguchi I (1980) Prediction of combined free and forced convective heat transfer along a vertical plate with blowing. ASME J Heat Transfer 102: 168-170

14. Watanabe T (1991) Forced and free mixed convection boundary layer flow with uniform suction or injection on a vertical flat plate. Acta Mechanica 89: 123-132

15. Hossain MA; Ahmed M (1990) MHD forced and free convection boundary layer flow over the leading edge. Int J Heat Mass Transfer 33: 571-575
16. Chen CH (1997) Non-Darcy mixed convection over a vertical flat plate in porous media with variable wall heat flux. Int Comm Heat Mass Transfer 24: 427-438

17. Lee KT; Yan WM (1998) Mixed convection heat transfer in horizontal ducts with wall temperature effect. Int J Heat Mass Transfer 41: 411-424

18. Harris SD; Ingham DB; Pop I (1998) Unsteady mixed convection boundary layer flow on a vertical surface in a porous medium. Int J Heat Mass Transfer 42: 357-372

19. Yan WM; Lin TF (1999) Radiation effects on laminar mixed convection in an inclined square duct. J Heat Transfer 121: 194200

20. Barletta A (1999) Analysis of combined forced and free convection in a vertical channel with viscous dissipation and isothermalisoflux boundary conditions. ASME J Heat Transfer 121: 349-356

21. Kumari M; Takhar HS; Nath G (2001) Mixed convection flow over a vertical wedge embedded in a highly porous medium. Heat Mass Transfer 37: 139-146

22. Takhar HS; Kumari M; Nath G (2001), Buoyancy effects in boundary layers on a continuously moving vertical surface with a parallel free stream. Arch Mech 53: 151-166

23. Blottner FG (1970) Finite-difference method of solution of the boundary layer equations. AIAA. J 8: 193-205

24. Eringen AC; Maugin GA (1990) Electrodynamics of Continua. Vol. 2, Springer Verlag, Berlin, Germany 